\title{
ASSESSING OF DAYLIGHT FACTOR VALUES DEPENDING ON WINDOW OPENING STRUCTURES IN MODEL ROOM
}

\author{
Milada BALKOVÁ \\ Slovak University of Agriculture in Nitra, Slovakia
}

\begin{abstract}
In this article, there are compared the types of opening structures in terms of their size and in terms of covering of opening structures with curtains or blinds. Two windows were used in the first case and three windows in the second case. In the third case, the window was divided into three parts, and in the fourth case, the window was divided into three parts covered with curtains. The size of opening structures in the first half of the room, near the windows, has the greatest impact on lighting. In the rear part of the room, the difference is not so great. If the windows are covered with curtains or blinds, the difference in room lighting is significant.
\end{abstract}

Keywords: daylight, daylight factor, opening structures, Wdls program

One of important factors for human health, in psychological but also physiological terms, is daylight. It affects humans not only in the domestic but also in the work environment. Therefore, it is necessary to make the most of daylight in the design of interiors intended for a permanent residence of people (STN 73 0580).

Daylight distribution in internal premises is determined by daylight factor values in monitoring points spaced in a regular network on a horizontal plane. In addition to direct measurement, daylight factor values can be determined using the Wdls 4.1 software, which is used as a universal program for daylight calculation according to ČSN 730580. The values of daylight factor in room depend on what type of activities are carried out there.

\section{Material and methods}

Daylight factor values have been considered in a model room, the ground plan dimensions of which are $6,000 \times$ $4,500 \mathrm{~mm}$. The room height was $2,700 \mathrm{~mm}$. The dimensions of opening structures were varied on a shorter wall, and one type was compared with the use of curtains, too. Due to the fact that glass doors were not considered, they are not plotted in the program. Daylight was evaluated in an empty room, with no obstacles.

We compared four types of opening structures. The sill height was the same for all types, $900 \mathrm{~mm}$. With the first type, there were two windows with dimensions $1,200 \times$ $1,500 \mathrm{~mm}$ on the shorter wall. With the second type, were three windows with dimensions $1,200 \times 1,500 \mathrm{~mm}$ on the shorter wall. With the third type, there was placed a triple window on the shorter wall, the height of which was 1,500 $\mathrm{mm}$ and was composed of three windows, the width of which was $630 \mathrm{~mm}, 1,140 \mathrm{~mm}$ and $630 \mathrm{~mm}$, respectively. All the three types were considered without being covered by curtains. The fourth type was the same as the third, but using curtains.

For all of the options, there were reached the same values of the reflectance factor of ceiling -0.7 , the reflectance factor of all the four walls -0.5 , floor reflectance -0.3 , field reflectance -0.2 , and reducing reflectance of exterior and interior -0.87 . The exterior and interior condition was considered pure. Two clear glasses were used everywhere, with the value of the transfer coefficient of one glass 0.92 , opening structure coefficient 0.75 , and building structure coefficient 1.0. A difference was in the coefficient of control devices, the value of which was 1.0 if the windows were not covered. In the case of using curtains, that value was 0.7 .

According to Decree No 541/2007 specifying requirements for lighting at work, as amended by Decree No $206 / 2011$, the value of daylight factor (D) should be at least $1.5 \%$ for daily side lighting. Window structures in the room were considered on the basis of that value.

\section{Results and discussion}

In the first type of opening structures, there were used two windows with dimensions $1,200 \times 1,500 \mathrm{~mm}$, with a clear double glazing without curtains (Figure 1). The resulting values of daylight factor in monitoring points are given in Table 1 as a percentage, where:

- minimum daylight factor value $D_{\text {min. }}=0.9 \%$;

- mean daylight factor value $D_{\text {mean }}=2.4 \%$;

- maximum daylight factor value $D_{\text {max. }}=9.8 \%$;

- uniformity of daylight (the ratio of the minimum and maximum value of daylight factor) $r_{\text {daily }}=0.094$.

In the second type of opening structures, there were used three windows with dimensions $1,200 \times 1,500 \mathrm{~mm}$, with a clear double glazing without curtains (Figure 2). The resulting values of daylight factor in monitoring points are given in Table 2 as a percentage, where:

- minimum daylight factor value $D_{\text {min. }}=1.4 \%$;

- mean daylight factor value $D_{\text {mean }}=3.5 \%$;

- maximum daylight factor value $D_{\text {max. }}=11.0 \%$;

- uniformity of daylight (the ratio of the minimum and maximum value of daylight factor) $r_{\text {daily }}=0.125$. 
Table 1 Room with two windows of 1,200 $\times 1,500 \mathrm{~mm}$

\begin{tabular}{|l||c|c|c|c|c|c|c|c|c|c|c|c|c|c|}
\hline $\begin{array}{l}\text { Y } \\
\text { Distance from the origin of } \\
\text { the coordinate system in } \mathbf{~ m m}\end{array}$ & $\mathbf{5 0 0}$ & $\mathbf{1 , 0 0 0}$ & $\mathbf{1 , 5 0 0}$ & $\mathbf{2 , 0 0 0}$ & $\mathbf{2 , 5 0 0}$ & $\mathbf{3 , 0 0 0}$ & $\mathbf{3 , 5 0 0}$ & $\mathbf{4 , 0 0 0}$ & $\mathbf{4 , 5 0 0}$ & $\mathbf{5 , 0 0 0}$ & $\mathbf{5 , 5 0 0}$ \\
\hline \hline 500 & 1.0 & 0.9 & 1.0 & 1.1 & 1.3 & 1.6 & 1.9 & 1.9 & 2.3 & 2.7 & 2.0 \\
\hline 1,000 & 1.0 & 0.9 & 1.0 & 1.1 & 1.3 & 1.6 & 2.0 & 2.4 & 2.9 & 4.3 & 5.9 \\
\hline 1,500 & 1.1 & 1.0 & 1.0 & 1.2 & 1.4 & 1.7 & 2.3 & 2.8 & 3.9 & 5.6 & 8.3 \\
\hline 2,000 & 1.1 & 1.0 & 1.0 & 1.2 & 1.4 & 1.8 & 2.4 & 2.9 & 4.2 & 6.9 & 9.4 \\
\hline 2,500 & 1.1 & 1.0 & 1.0 & 1.2 & 1.4 & 1.8 & 2.4 & 2.9 & 4.2 & 6.9 & 9.8 \\
\hline 3,000 & 1.1 & 1.0 & 1.0 & 1.2 & 1.4 & 1.7 & 2.2 & 2.6 & 3.7 & 5.6 & 8.1 \\
\hline 3,500 & 1.0 & 0.9 & 1.0 & 1.1 & 1.3 & 1.6 & 2.0 & 2.2 & 2.9 & 4.2 & 5.4 \\
\hline 4,000 & 1.0 & 0.9 & 1.0 & 1.1 & 1.3 & 1.5 & 1.7 & 1.8 & 2.2 & 2.2 & 1.6 \\
\hline
\end{tabular}

Table 2 Room with three windows of $1,200 \times 1,500 \mathrm{~mm}$

\begin{tabular}{|l||c|c|c|c|c|c|c|c|c|c|c|c|c|}
\hline $\begin{array}{l}\text { YIX } \\
\text { Distance from the origin of } \\
\text { the coordinate system in } \mathbf{~ m m}\end{array}$ & $\mathbf{5 0 0}$ & $\mathbf{1 , 0 0 0}$ & $\mathbf{1 , 5 0 0}$ & $\mathbf{2 , 0 0 0}$ & $\mathbf{2 , 5 0 0}$ & $\mathbf{3 , 0 0 0}$ & $\mathbf{3 , 5 0 0}$ & $\mathbf{4 , 0 0 0}$ & $\mathbf{4 , 5 0 0}$ & $\mathbf{5 , 0 0 0}$ & $\mathbf{5 , 5 0 0}$ \\
\hline \hline 500 & 1.5 & 1.4 & 1.5 & 1.7 & 1.9 & 2.4 & 2.9 & 3.5 & 4.1 & 5.1 & 7.4 \\
\hline 1,000 & 1.5 & 1.4 & 1.5 & 1.7 & 2.0 & 2.4 & 3.1 & 3.9 & 4.5 & 6.9 & 8.6 \\
\hline 1,500 & 1.6 & 1.5 & 1.5 & 1.7 & 2.0 & 2.6 & 3.3 & 4.2 & 5.1 & 7.2 & 11.0 \\
\hline 2,000 & 1.6 & 1.5 & 1.6 & 1.8 & 2.1 & 2.6 & 3.4 & 4.5 & 5.3 & 7.6 & 9.8 \\
\hline 2,500 & 1.6 & 1.5 & 1.6 & 1.8 & 2.1 & 2.6 & 3.4 & 4.4 & 5.1 & 7.2 & 9.9 \\
\hline 3,000 & 1.6 & 1.5 & 1.5 & 1.7 & 2.0 & 2.5 & 3.3 & 4.2 & 4.8 & 7.2 & 10.6 \\
\hline 3,500 & 1.5 & 1.4 & 1.5 & 1.7 & 2.0 & 2.4 & 3.0 & 3.8 & 4.5 & 6.9 & 8.6 \\
\hline 4,000 & 1.5 & 1.4 & 1.5 & 1.7 & 1.9 & 2.3 & 2.9 & 3.5 & 4.0 & 5.2 & 7.4 \\
\hline
\end{tabular}

In the third type of opening structures, there was used a triple window with dimensions $(630+1,140+630) \times 1,500$ $\mathrm{mm}$, with a clear double glazing without curtains (Figure 3 ). The resulting values of daylight factor in monitoring points are given in Table 3 as a percentage, where:

- minimum daylight factor value $D_{\text {min. }}=0.9 \%$;

- mean daylight factor value $D_{\text {mean }}=2.3 \%$;

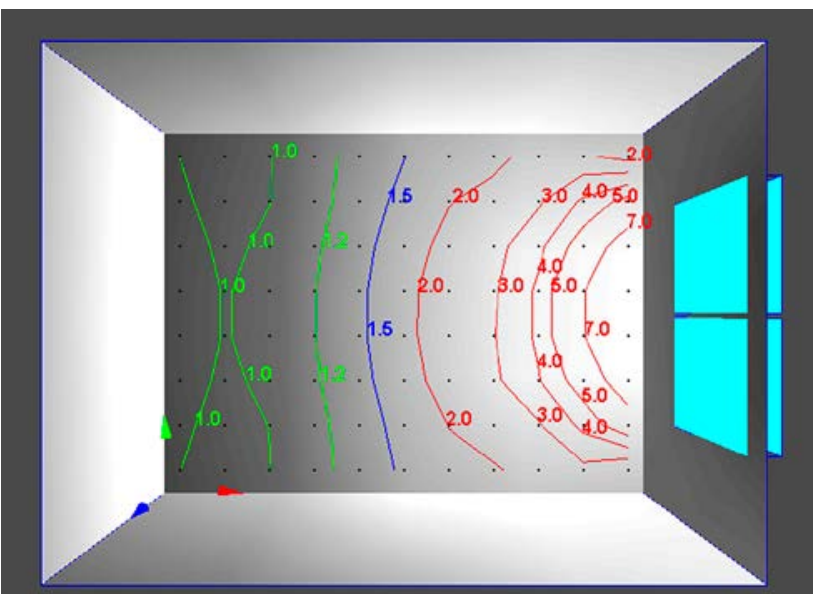

Figure 1
- maximum daylight factor value $D_{\text {max. }}=8.9 \%$;

- uniformity of daylight (the ratio of the minimum and maximum value of daylight factor) $r_{\text {daily }}=0.105$.

In the fourth type of opening structures, there was used a triple window with dimensions $(630+1,140+630) \times 1,500$ $\mathrm{mm}$, with a clear double glazing with curtains (Figure 4 ). The

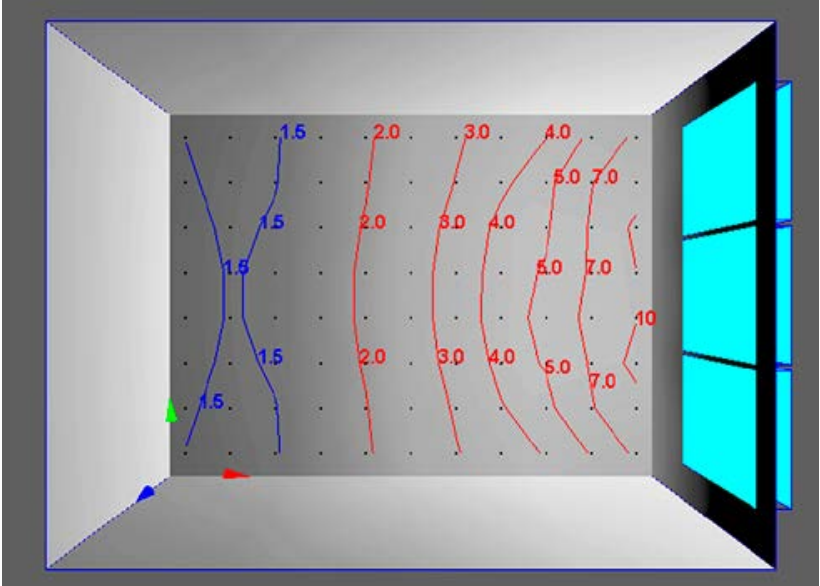

Figure 2 Room with three windows

Legend to Figures 1-4: • green colour of isolines - values of daylight factor lower than the minimum value of daylight factor according to Decree No 206/2011; • blue colour of isolinies - the minimum value of daylight factor according to Decree No $206 / 2011$; red colour of isolines - values of daylight factor higher than the minimum value of daylight factor according to Decree No $206 / 2011$ 
Table 3

Room with a triple window of $(630+1,140+630) \times 1,500 \mathrm{~mm}$ without curtains

\begin{tabular}{|l||c|c|c|c|c|c|c|c|c|c|c|c|c|c|}
\hline $\begin{array}{l}\text { YIX } \\
\text { Distance from the origin of } \\
\text { the coordinate system in } \mathbf{~}\end{array}$ & $\mathbf{5 0 0}$ & $\mathbf{1 , 0 0 0}$ & $\mathbf{1 , 5 0 0}$ & $\mathbf{2 , 0 0 0}$ & $\mathbf{2 , 5 0 0}$ & $\mathbf{3 , 0 0 0}$ & $\mathbf{3 , 5 0 0}$ & $\mathbf{4 , 0 0 0}$ & $\mathbf{4 , 5 0 0}$ & $\mathbf{5 , 0 0 0}$ & $\mathbf{5 , 5 0 0}$ \\
\hline \hline 500 & 1.0 & 0.9 & 1.0 & 1.1 & 1.3 & 1.5 & 1.8 & 2.0 & 2.1 & 1.9 & 1.4 \\
\hline 1,000 & 1.0 & 1.0 & 1.0 & 1.1 & 1.3 & 1.6 & 2.0 & 2.5 & 2.6 & 3.9 & 4.5 \\
\hline 1,500 & 1.1 & 1.0 & 1.0 & 1.2 & 1.4 & 1.7 & 2.3 & 3.0 & 3.5 & 5.5 & 8.1 \\
\hline 2,000 & 1.1 & 1.0 & 1.1 & 1.2 & 1.4 & 1.8 & 2.4 & 3.3 & 4.0 & 6.2 & 8.9 \\
\hline 2,500 & 1.1 & 1.0 & 1.1 & 1.2 & 1.4 & 1.8 & 2.4 & 3.3 & 4.0 & 6.1 & 8.7 \\
\hline 3,000 & 1.1 & 1.0 & 1.0 & 1.2 & 1.4 & 1.7 & 2.2 & 2.9 & 3.4 & 5.6 & 8.1 \\
\hline 3,500 & 1.0 & 1.0 & 1.0 & 1.1 & 1.3 & 1.6 & 2.0 & 2.4 & 2.7 & 3.6 & 4.6 \\
\hline 4,000 & 1.0 & 0.9 & 1.0 & 1.1 & 1.3 & 1.5 & 1.8 & 2.0 & 1.9 & 1.7 & 1.4 \\
\hline
\end{tabular}

Table 4

Room with a triple window of $(630+1,140+630) \times 1,500 \mathrm{~mm}$ with curtains

\begin{tabular}{|c|c|c|c|c|c|c|c|c|c|c|c|}
\hline \multirow{2}{*}{$\begin{array}{l}\text { YIX } \\
\text { Distance from the origin of } \\
\text { the coordinate system in } \mathrm{mm}\end{array}$} & 500 & 1,000 & 1,500 & 2,000 & 2,500 & 3,000 & 3,500 & 4,000 & 4,500 & 5,000 & 5,500 \\
\hline & \multicolumn{11}{|c|}{ Daylight factor values in monitoring points in \% } \\
\hline 500 & 0.7 & 0.6 & 0.7 & 0.8 & 0.9 & 1.0 & 1.2 & 1.3 & 1.3 & 1.3 & 1.0 \\
\hline 1,000 & 0.7 & 0.6 & 0.7 & 0.8 & 0.9 & 1.1 & 1.3 & 1.5 & 2.0 & 2.4 & 3.3 \\
\hline 1,500 & 0.7 & 0.7 & 0.7 & 0.8 & 0.9 & 1.2 & 1.5 & 1.8 & 2.5 & 4.1 & 6.0 \\
\hline 2,000 & 0.7 & 0.7 & 0.7 & 0.8 & 1.0 & 1.2 & 1.6 & 2.0 & 2.8 & 4.4 & 5.8 \\
\hline 2,500 & 0.7 & 0.7 & 0.7 & 0.8 & 1.0 & 1.2 & 1.6 & 1.9 & 2.7 & 4.5 & 5.9 \\
\hline 3,000 & 0.7 & 0.7 & 0.7 & 0.8 & 0.9 & 1.2 & 1.5 & 1.7 & 2.5 & 4.1 & 5.4 \\
\hline 3,500 & 0.7 & 0.6 & 0.7 & 0.8 & 0.9 & 1.1 & 1.2 & 1.5 & 2.0 & 2.4 & 3.3 \\
\hline 4,000 & 0.7 & 0.6 & 0.7 & 0.8 & 0.8 & 1.0 & 1.1 & 1.2 & 1.3 & 1.3 & 0.8 \\
\hline
\end{tabular}

resulting values of daylight factor in monitoring points are given in Table 4 as a percentage, where:

- minimum daylight factor value $D_{\text {min. }}=0.6 \%$;

- mean daylight factor value $D_{\text {mean }}=1.5 \%$;

- maximum daylight factor value $D_{\max }=6.0 \%$;

- uniformity of daylight (the ratio of the minimum and maximum value of daylight factor) $r_{\text {daily }}=0.105$.

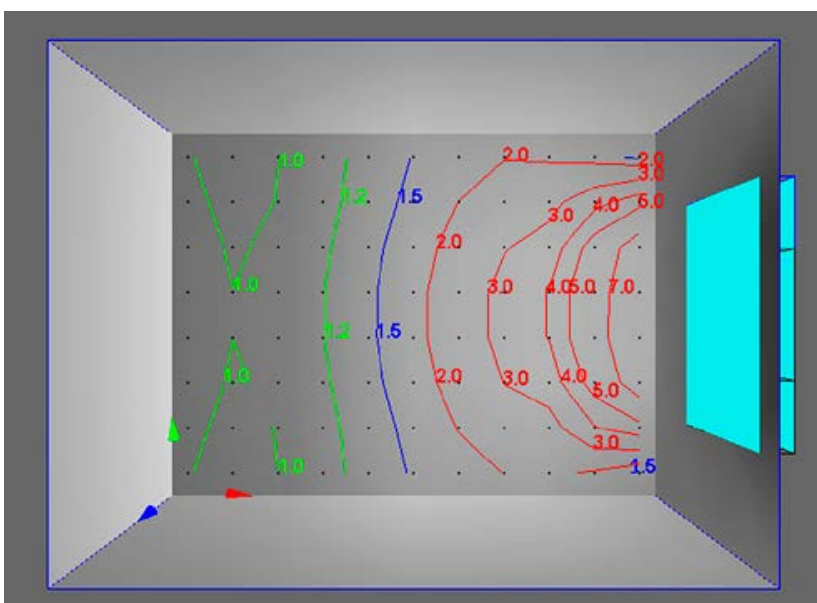

Figure 3

Room with a triple window without curtains
The graphs in Figure 5 and 6 provide a better comparison of room lighting for different types of window openings and covering. Figure 5 shows the comparison of daylight factor in the room with dimensions $6.0 \times 4.5 \mathrm{~m}$, depending on the window openings at a distance of $2,500 \mathrm{~mm}$ from the origin of the coordinate system in the direction of $y$-axis, which is approximately in the middle of the room. Figure 6 contains

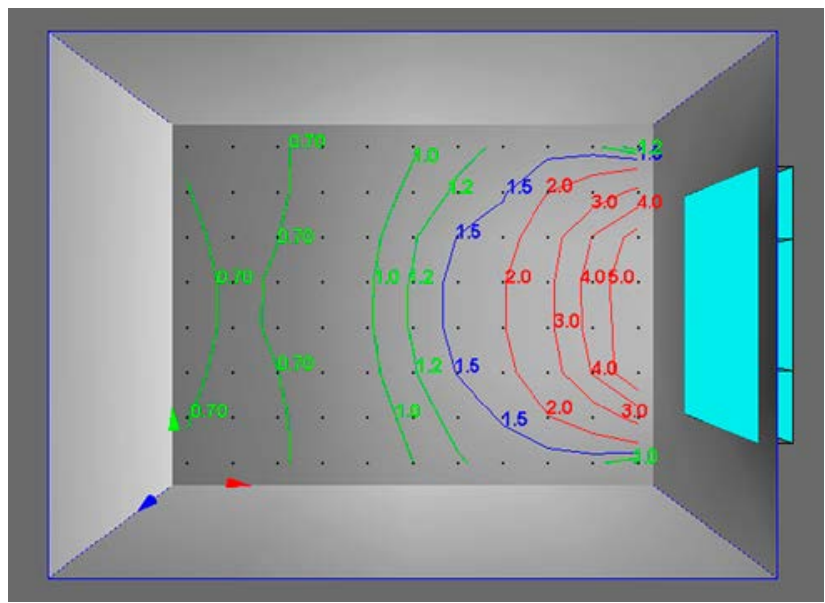

Figure 4 Room with a triple window with curtains

Legend to Figures 1-4: • green colour of isolines - values of daylight factor lower than the minimum value of daylight factor according to Decree No 206/2011; • blue colour of isolinies - the minimum value of daylight factor according to Decree No $206 / 2011 ; \cdot$ red colour of isolines - values of daylight factor higher than the minimum value of daylight factor according to Decree No $206 / 2011$ 


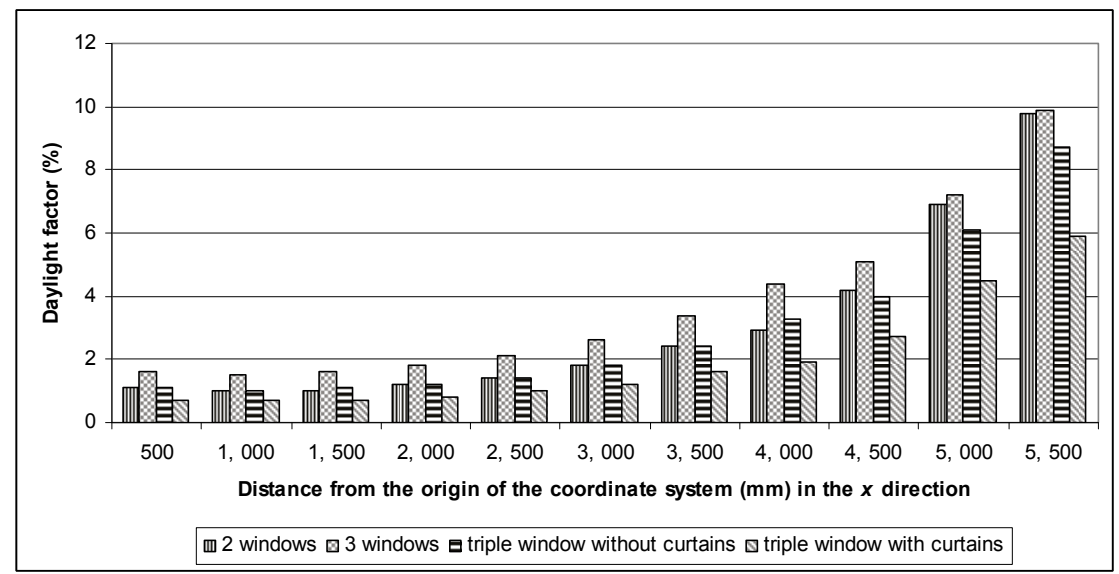

Figure 5 Comparison of daylight factor in the room with dimensions $6.0 \mathrm{~m} \times$ $4.5 \mathrm{~m}$, depending on window openings at a distance of $2,500 \mathrm{~mm}$ from the origin of the coordinate system in the $y$ direction

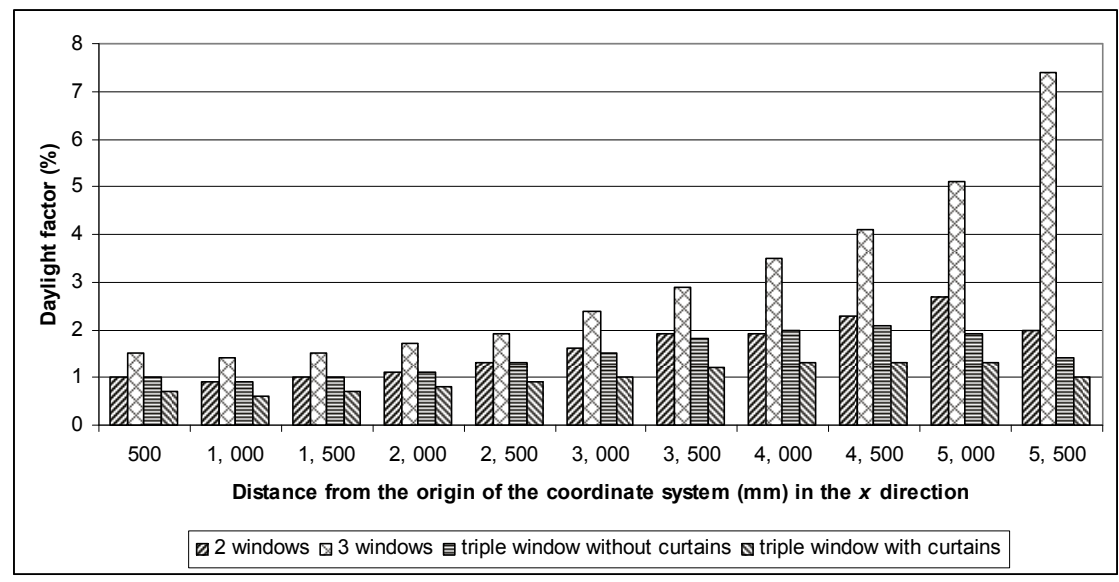

Figure 6 Comparison of daylight factor in the room with dimensions $6.0 \mathrm{~m} \times$ $4.5 \mathrm{~m}$, depending on window openings at a distance of $2,500 \mathrm{~mm}$ from the origin of the coordinate system in the $y$ direction

the comparison of daylight factor in the same room, at a distance of $500 \mathrm{~mm}$ from the origin of the coordinate system in the direction of $y$-axis, which is the extreme part of the room.

Figure 6 Comparison of daylight factor in a room with dimensions $6.0 \mathrm{~m}$ $\times 4.5 \mathrm{~m}$, depending on the window openings at a distance of $500 \mathrm{~mm}$ from the origin of the coordinate system in the $y$ direction

\section{Conclusion}

When assessing the lighting in room, we must especially know what purpose do not need much daylight. The most even illumination and hence the most of daylight is obtained with the second type where there are three windows without covering. Work tables can be placed in the entire room, while artificial light can be used after dark or in case of a very cloudy sky. The third type with one window divided into three parts is illuminated with daylight similarly to the first type. In the fourth case, we compare what is the difference in room lighting where the window is composed of three parts covered with curtains or blinds. Lighting conditions in the room are much worse.

It follows that the size of opening structures, especially in the first half of the room which is located near the windows, has the greatest impact. These differences are balanced in the rear part of the room. Therefore, when there is needed to work in the room with a greater depth and it is not possible to perform window openings elsewhere, or to propose skylights, artificial lighting must be used in these parts during the day.

\section{References}

RYBÁR, P. 1997. Štandardná metodika. Meranie a hodnotenie osvetlenia. MZ SR. $1997.35 \mathrm{~s}$.

STN 73 0580-1. 1986. Denné osvetlenie budov. Čast' 1: Základné požiadavky.

VYHLÁŠKA MZ SR č. 541/2007 Z. z. o podrobnostiach o požiadavkách na osvetlenie pri práci v znení vyhlášky MZ SR č. 206/2011 Z. Z. used as a study room, it is important that there is sufficient daylight. According to Decree No 206 of 2011, in indoor premises or in their functionally defined parts with a long-term stay of workers, the lowest allowable value of daylight factor for side light is $D_{\text {min. }}=$ $1.5 \%$.

With the first type where there are two windows without curtains or blinds, only the rear part of the room does not have sufficient daylight. In this case, the rear part of the room can be used for such work activities that

\section{Contact address:}

Ing. Milada Balková, PhD., Slovak Faculty of Engineering, Department of Structures, Tr. A. Hlinku 2, 94976 Nitra, Slovak Republic, e-mail: milada. balkova@uniag.sk University of Agriculture in Nitra, 